\title{
Impromptu Speaking And Interpretation Studies: A Preliminary Study
}

\author{
Michael Heinz, Hankuk University of Foreign Studies, Republic of Korea
}

\begin{abstract}
The purpose of this preliminary study was to look at forensics-based competition events and determine what, if any, impact they could have on the language learning and public speaking skills of interpreters in training. This paper details the nature of the impromptu and extemporaneous speaking events in forensics competitions and introduces a classroom activity styled after those events for interpreting language skills training. Specifically the classroom activity was designed to address the issues of utilizing B language (English) with little preparation, without the use of notes, and in a pressure environment. The study was based on several questions: Could students benefit from high intensity, impromptu speaking exercises in which they could not use notes during their delivery? Would this help them reduce their dependency on note taking? Would it improve their public speaking skills? Would it help them deal with high pressure situations? A survey of students' self-assessed skills was given before and after the classroom activity, in which 22 Interpretation and Translation graduate school students participated to determine if any progress could be made through the process. Students were asked to self-assess their: dependency on notetaking, dependency on intensive preparation, ability to persuade others, ability to cope with the stress of public speaking, ability to use English when speaking publically, overall public speaking ability, impromptu speaking ability, and public speaking experience. The overall results were positive in that students saw some progress in every category; with the highest category being in public speaking experience.
\end{abstract}

Keywords: Interpretation; Impromptu Speaking; Extemporaneous Speaking; Forensics; Note-Taking

\section{INTRODUCTION}

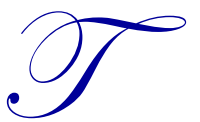

he relevancy of language learning in the field of interpretation and translation is unquestionable. According to Neubert, "There would be no grounds for transfer competence without the translator's thorough grounding in language competence and subject competence" (1995: 412). In particular, languages that are more distantly related or languages in which interpreters are required to interpret into their second language (B language) require additional language training to ensure success (Minns, 2002: 38). For the most part, foreign language learning programs take a general approach to language learning that may not be specific enough to meet the needs of interpreters and those training to be interpreters. Le Feal notes that the goal for interpreters is to perfect their language skills, not to simply obtain them (2000: 9). The process of developing language learning tasks specific to the needs of interpreters is the focus of this research. This research examined the interpretation field and identified several distinct aspects of interpretation and designed a particular classroom activity around those aspects and measured its efficacy. The specific aspects of interpretation identified were: the impromptu or extemporaneous nature of the task, the inability to completely depend upon note taking, and the overall pressure or stress generated by the task.

The first identified aspect, the ability to speak extemporaneously or in an impromptu fashion, is a skill required of all interpreters. Unless speakers provide an interpreter with a transcript of everything they intend to say, the task of interpretation is one in which extemporaneity is an unavoidable factor. More generally it is the impromptu nature of speech itself that defines, in part, the difference between interpretation and translation. Additionally, impromptu or extemporaneous speech fits the communicative model of language learning that is considered the dominant model in language learning today and is considered an appropriate model for language 
learning tasks for interpreters and translators (Colina, 2002: 5). The significance of this aspect of interpretation made it the primary focus of this study.

Though not as significant as extemporaneity, note-taking is an important part of interpretation. Of note however, is the inability to encapsulate all information given by the speaker even when taking notes. Morell goes even further and suggests that note-taking can, if improperly controlled, become a hindrance to the interpreter instead of assisting him or her (2011: 113). Within the program in which this research and the classroom activity were conducted, the author noted a tendency among the students during class to be commonly over-reliant on notetaking. As such, lowering students' dependency on note-taking and increasing their faith in their meta-cognitive skills became an additional concern.

The third concern or aspect, the overall pressure or stress related to the process of interpretation, is something of a quandary in terms of explaining its relevance. It is unclear whether interpretation-related stress is inherent to the process, as some interpreters note feelings of euphoria or exhilaration during the process of interpretation. As such, the stress related to interpretation may be more related to feelings regarding linguistic, subject, or transference competency. That being said, it is safe to assume that new tasks are somewhat stressful for individuals, and events that require instantaneous results, and that cannot be easily corrected, are high pressure events. Moreover, the work environment for interpreters is considered to be a hostile one in terms of the amount of distractions and the immediate output that the audience desires from the interpreter (Morell 2011).

Extemporaneity, note-taking over-reliance, and the need for high pressure environment functionality by no means sum up all the specific aspects of interpretation. These aspects are however all things that can be improved upon within language learning tasks and as such formed the basis for this research. The essential focus of this study was: how to build appropriate extemporaneous language tasks that will challenge students to produce language without significant periods for preparation, force them to manage relatively complex information through the use of their memory faculties, as opposed to using notes, and how to feel more confident about the process of performance in which extemporaneity is required and second chances are not an option? To this end an exercise was developed by considering the direct observation of students training to be interpreters, looking at interpretation as a task, and examining the field of forensics and its understanding of impromptu and extemporaneous exercises. To assess the classroom activity developed in terms of its efficacy, students in a graduate level interpretation and translation program were asked to assess their speaking skills before and after the activity. This paper begins by looking at the field of forensics and assesses the usefulness of their impromptu and extemporaneous speaking tasks with regards to training interpreters. After that the students that participated in this study are profiled, the methodology of the study and details of the classroom exercise are explained thoroughly before examining the results of students' perceived improvements. Beyond that some closing remarks and suggestions for further study bring this paper to a close.

\section{LITERATURE REVIEW}

To begin, interpreters obviously require a high-level linguistic aptitude to do their job well, and it logically follows that intense language training is required to reach that level. However, students of interpretation and translation often approach language learning ineffectively, seeking only to enhance their vocabulary or the total number of expressions they know in their B language (Donovan 2004). Additionally many students simply look to professors of interpretation and translation to give them ready-made interpretations of common expressions from the A language into their B language (Lim 2001). These simplistic approaches are forms of language learning with an aim towards language acquisition, whereas interpreters are more focused on mastering previously acquired language (Le Feal 2000). With this in mind, the author turned towards the fields of forensics, wherein native language speakers challenge their language skills in their mother tongue in terms of mastery.

Forensics in this research refers not to crime scene investigation techniques, otherwise known as "forensic science," but instead to the field of argumentation and in particular the collegiate competitions that they hold. Additionally, there are many forms of forensic competition, but this paper examines the usefulness of the impromptu and extemporaneous speech events.

The titles of both the impromptu and extemporaneous speech events are essentially synonymous to the casual observer, but within the field of forensics their titles denote specific differences. In the impromptu speech 
event, participants are given a quotation as a prompt, given as little as thirty seconds to prepare, and then asked to give a speech of around 5 minutes that may be in favor of the prompt, opposed to the prompt, or an analysis of the prompt. In the extemporaneous speech event, participants are given a specific question usually related to current events, around 30 minutes of preparation time, an opportunity to create an evidence file in advance, and roughly 7 minutes to give a speech answering the question. These rules are consistent with the general guidelines put forth by the National Forensic Association.

While the details of the rules related to each event may vary, the basic goals and techniques employed by participants do not vary. Both events offer a number of benefits as classroom activities for interpreters. Firstly, forensics events require students to utilize the language used in public speaking, which as Nolan points out is different from the type of language utilized in everyday speech (2005). Moreover, Nolan recommends a number of argumentation-related exercises similar to the aforementioned forensics events (2005).

Since, as Lim points out, interpretation studies are a market-driven field based in practical application, language tasks need to be experiential in nature (2001). Advocating the experiential dimension of forensics, Sellnow notes that forensics exercises require participants to substantiate statements, understand contemporary issues, and spontaneously utilize public speaking skills in a setting that simulates situations beyond the classroom (1994). Reynolds and Fay also describe the ideal impromptu competitor as possessing, "abilities of poise, humor, organization, and synthesis, combined with invention and memory" (1987). With perhaps the exception of humor, all of those qualities could be used to describe an ideal interpreter.

However, impromptu and extemporaneous speaking events must be constructed with some caution. Anyone that has run debate competitions or public speaking exercises will note the tendency of participants to use generic examples or cliché examples that undermine the activities' goal of engaging a broad range of knowledge. Williams, Carver, and Hart point out, "The consistent use, and overuse, of Adolph Hitler and the actions of Nazi Germany is the predominant example of this problem. The problem with generic examples is that they limit the student's use of analysis and invention and focus more on attempts at developing links between familiar examples" (1993). Yet they also offer good advice as to how one can counteract this problem by creating specific prompts that avoid vagueness, and they require the use of more specific examples (1993).

Of additional concern is the impromptu event's openness, which results from its being based on responding to or building upon a specific, but often vague quotation. This event tends to reward glibness or stretching information to lengthen a response (Williams, Carver \& Hart 1993). As such, the structure of the extemporaneous event is better suited for interpreter training because it is more focused and related to current events. Additionally, the extemporaneous speaking event requires students to be concise and mobilize considerable information to establish a strong argument or presentation. Yet it is likely that in attempting to implement the extemporaneous speaking event in a classroom that instructors will have to reduce the preparation time to fit class times. In the methodology section of this paper, the author details the specific alterations made to the impromptu and extemporaneous events needed to give them maximum relevancy to interpreter training.

\section{STUDENT PROFILE}

The students that participated in this experiment were all first year students in the author's Debate and Current Issues class at the Hankuk University of Foreign Studies Graduate School of Interpretation and Translation (HUFS GSIT). HUFS GSIT offers a two-year program to students of interpretation and translation, and upon passing this program students become certified interpreters.

The backgrounds of students participating in the HUFS GSIT program vary as do their initial language levels. The 22 students that participated in this experiment were from two different sections of the same course. All were of Korean ethnic origin and claimed Korean as their mother tongue. The students in the study are predominantly women in their mid- to late twenties and the majority of them have spent at least a year or two living outside of the Republic of Korea. Discussions with students have repeatedly highlighted that the vast majority of students, prior to entering HUFS GSIT, did not do an extensive amount of public speaking in their undergraduate programs in Korea, although a minority of students did report having done some public speaking tasks abroad in 
mostly western undergraduate or high school programs. Within the first semester of the program, most students report great difficulty in giving a single 4-6 minute persuasive speech in front of the class. It is the view of the author that the initial performances of students are typically characterized by visible signs of duress that significantly impedes the students' ability to communicate any message effectively. The experiment took place in the second semester of the students' first year at HUFS GSIT, and prior to the experiment most students had delivered 3 to 5 public speeches or presentations during in-class activities in English support classes within the program.

\section{METHODOLOGY}

Students were given a survey (Appendix A) that asked for their current self-assessment regarding their skills. The survey asked students to rate 8 skills on a scale of 1 to 10 , with 1 being low and 10 being high. The items were: dependency on using notes while giving a public speech, dependency on intensive preparation, ability to persuade others or advocate a position, ability to cope with the stress of public speaking, ability to use English when speaking publically, overall public speaking ability, impromptu speaking ability, and public speaking experience. There are a limited range of skills that can be improved in B language support classes, so the items were selected on the basis of skills that could reasonably be observed in a B language support class and on their applicability to interpretation studies. Overall interpretation skills were not included as an item because they are not observable in a B language support class.

The classroom activity upon which the study was conducted required careful planning and execution. In order to achieve the study's goal of creating an impromptu speaking exercise that reduced dependency on notes and simulated high pressure situations, a number of key factors had to be considered: overall curriculum concerns, total class time, class participation, the need for content-rich input and output, and limited preparation time.

In terms of its place within the curriculum, the study's in-class activity was presented as a final exercise to push the students' limits and help them evolve as public speakers and interpreters. Class time was limited to 100 minutes per class, once per week, and each class had 10-12 students. The activity took place during four 100 minute class periods and required about 50 minutes to introduce in a class that took place before study's in-class activity, at which time the students were also given a survey of their speaking skills.

Within each of the four classes in which the study's in-class activities were conducted, the structure of the class was the same. The author used about 50-60 minutes worth of class time to present a topic. The nature of this presentation varied on the basis of the topic and materials available, but generally consisted of videos and short articles that presented the main points of view regarding the issues. Students engaged the materials and were given a short opportunity to ask questions for clarification. During this period of the class, students were allowed to take notes on the topic at hand. After that, students were selected randomly via a random number generator to give a 3 to 5-minute impromptu speech on the topic based on a particular prompt. Students were given ten minutes to prepare in isolation and were able to use their notes. During the ten minutes, they were asked to draft an outline of their impromptu speech as well. After their ten minutes were up, the students had to relinquish all notes and their outline and give the speech in front of the class. Specific attention was given to timing to ensure that each student had only ten minutes to prepare. After a student's speech, another student was randomly selected to give a oneminute rebuttal to the impromptu speech. Depending on the class size, each class included two to three impromptu speeches, giving students an opportunity to make one 3- to 5-minute impromptu speech and a single one-minute rebuttal over the course of the four week activity. So in a single class, 3- to 4- randomly selected students would speak about the same topic, using different prompts and 3- to 4- students would additionally attempt to rebut their speeches.

The details of the activity were painstakingly crafted to ensure achievement of the goal of creating an activity that challenged students to give an impromptu speech in a high pressure environment without notes. The key details that were utilized to achieve this goal were: random student selection for impromptu speeches and rebuttals, and topic selection. In order to ensure students' speeches would be impromptu, students were selected randomly and had no prior knowledge of the possible prompts. Furthermore, digital timers were used to guarantee that students had only ten minutes to consider their speech. Class participation was a general concern, given that the 
activity took place within an active course, so selecting students randomly for impromptu speeches and rebuttals had the added effect of keeping students keenly focused during the professor's presentation and their classmates' speeches. As such students were forced to constantly participate in the classroom activity through active listening. More significantly, the random selection created a high pressure situation that did not require advanced machinery to detect. Students looked visibly distressed and frequently failed to restrain themselves from voicing consternation and concern about their ability to perform under tight constraints.

In addition to the use of random student selection, topic selection played a key role in achieving the goals of the exercise. Topics were selected on the basis of several factors. First, it was important that the students had not dealt with the topic in class before to make sure that it would challenge them in a manner similar to the way in which a freelance interpreter often must learn about a topic on short notice. Second, it was important that the topic was something intellectually challenging for a graduate-level student. Third, it was critical that the topic not be a forensic cliché like the death penalty or corporal punishment, so that students were forced to understand and construct new perspectives within the class period. The topics selected were: Trans-humanist thought and the future of the genetic modifications of humans, free trade vs. fair trade, intellectual property rights, and whether or not foreign aid is an appropriate way to help developing nations. All of these topics seemed to challenge the students intellectually.

Given the intellectually challenging nature of the topics, speech prompts were fairly simple. In general, most of the prompts required taking a position in favor of one side of the issue, and giving a speech that supported that perspective. Some other prompts required critiquing the argument related to one side of the topic. As a result of the short time the students had to prepare, it was essential that the prompt be clear and simple so that they could maximize their preparation time. Generally students were quick to apprehend their given prompt and worked diligently within the preparation period. An example prompt being: give a speech in favor of free trade agreements based on the material you have just been exposed to in this study.

Undoubtedly the desire to obtain a high grade on the exercise was a strong motivational factor. Students were graded on the basis of several broad categories: content, delivery, and organization. In terms of content, students were judged on the basis of the relevance of examples employed and the student's ability to utilize information presented in the first half of the class. With regard to delivery, students were evaluated based on their ability to make authentic eye contact, speak with conviction, properly enunciate, and use their English to make their ideas easily understood. The organizational requirements were: placing a clear thesis at the beginning of the speech, showing some sign of structure by previewing the contents of the speech in the introduction, and providing clear transitions between main ideas.

\section{FINDINGS}

The findings of the study can be summarized as being positive. In every category, some improvement was reported by the students, though the standard deviation varied greatly in nearly all categories. Additionally, students were encouraged after the in-class exercise to give verbal feedback and/or written feedback. This feedback will be included in the discussion of the data.

In terms of dependency on notes and dependency on intensive preparation via memorization of speeches, students reported a reduction in both categories. These items were looking for negative values to show progress so their results are grouped together to avoid confusion. Regarding the dependency on notes item, the difference between the pre-exercise mean $(\mathrm{M}=5.59091, \mathrm{SD}=2.34336)$ and the post-exercise mean $(\mathrm{M}=4.77273, \mathrm{SD}=$ 2.6714) was -0.81818 , which shows an overall reduction in note-taking dependency. Regarding the dependency on intensive preparation (memorizing a speech) item, the difference between the pre-exercise mean $(\mathrm{M}=6.04545$, SD $=2.45875)$ and the post-exercise mean $(\mathrm{M}=5.09091, \mathrm{SD}=2.4085)$ was -0.95454 , which shows an overall decrease in intensive preparation dependency. 


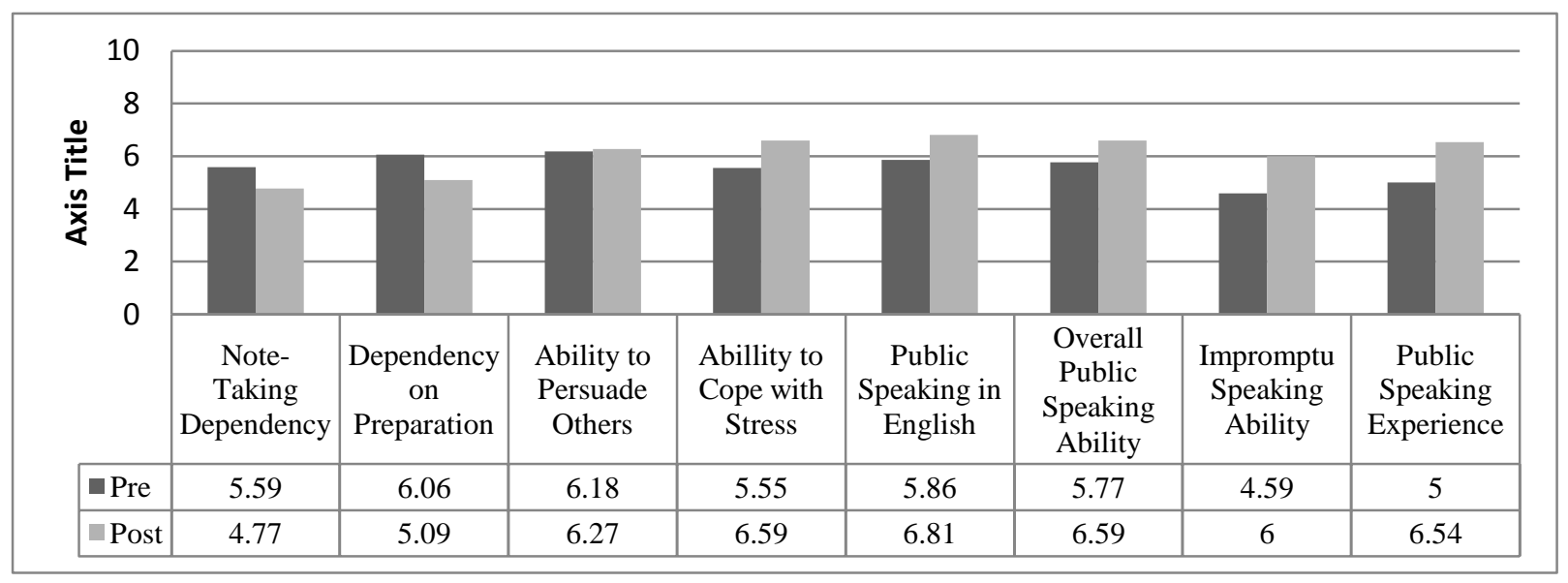

[Fig 1] Students' Self-Assessment of Skills Pre-Exercise and Post-Exercise

Additionally, one student wrote that the exercise "helped me to realize I don't need notes." The results were significant because beginner HUFS GSIT students tend to fall into the bad habit of reading public speeches word for word, diminishing the performance of their public speaking.

Interestingly, students reported very little change in their persuasive ability. Regarding the ability to persuade others or advocate a position item, the difference between the pre-exercise mean $(\mathrm{M}=6.18182, \mathrm{SD}=$ $2.12998)$ and the post-exercise mean $(\mathrm{M}=6.27273, \mathrm{SD}=1.83048)$ was +0.09091 , which was not a significant increase. Based on classroom observation, the difficulty of the exercise seemed to reduce the final performance aspect of their public speaking. Students seemed to struggle with ability to retain new information and reproduce it in an organized fashion.

In terms of stress management, the results were positive, but student comments raised some interesting questions. Regarding the ability to cope with the stress of public speaking item, the difference between the preexercise mean $(\mathrm{M}=5.54545, \mathrm{SD}=2.44418)$ and the post-exercise mean $(\mathrm{M}=6.59091, \mathrm{SD}=2.34336)$ was +1.04546 , which was a positive result. Verbally, many students commented that the exercise helped them think more about their strategies for dealing with public speaking or performance stress. The written comments of students contained one strong validation of the process and two intriguing comments. In terms of validation, one student wrote that it was necessary to expose students to the kind of pressure generated by the exercise due to the nature of the interpretation profession. A different student wrote that they feel more stress when speaking publically in English (B Language), as opposed to Korean (A Language), and wondered if the stress was the result of poor stress management or poor linguistic ability. Another student wrote "while the impromptu speech exercises were helpful and resourceful, I think my stage fright is a mental problem" (this student rated their coping ability at a score of 1). Both of the latter comments raise interesting questions about stress management with regard to interpretation pressure.

Generally students felt that their English skills and public speaking skills improved as a result of the exercise. Regarding the ability to use English when speaking publically item, the difference between the preexercise mean $(\mathrm{M}=5.86364, \mathrm{SD}=2.03061)$ and the post-exercise mean $(\mathrm{M}=6.81818, \mathrm{SD}=1.68003)$ was +0.95454 , which was a positive result. Regarding the overall public speaking ability item, the difference between the pre-exercise mean $(\mathrm{M}=5.77273, \mathrm{SD}=1.90067)$ and the post-exercise mean $(\mathrm{M}=6.59091, \mathrm{SD}=1.40269)$ was +0.81818 , which was also a positive result. In class, verbal comments indicated that many students were pleased with their linguistic growth and their general public speaking ability as a result of this exercise. One student wrote that they felt they needed to do more public speaking in class, but this seemed to be more of a comment about the course's curriculum and not the specific exercise related to this study. Another student wrote that "it helped me understand that I need to work on my confidence rather than skills or proficiency itself." This comment suggests that for at least one student this exercise helped them understand the need for interpreters to move towards mastering their existing language skills instead of trying to acquire more and more linguistic knowledge (Lim 2001). 
Predictably, students reported a significant improvement in impromptu speaking, but unexpectedly reported significant gains in their overall public speaking experience. With regard to the impromptu speaking ability item, the difference between the pre-exercise mean $(\mathrm{M}=4.59091, \mathrm{SD}=1.99187)$ and the post-exercise mean $(\mathrm{M}=6, \mathrm{SD}$ $=1.57359)$ was +1.40909 , which was the second largest reported change in the study. With regard to the public speaking experience item, the difference between the pre-exercise mean $(\mathrm{M}=5, \mathrm{SD}=2.50713)$ and the postexercise mean $(\mathrm{M}=6.54545, \mathrm{SD}=2.15423)$ was 1.54545 , which was the largest change in any item on the survey. The large increase in student's impromptu speaking ability was predictable given that the exercise was an impromptu speaking exercise, so it stands to reason that impromptu speaking would improve the most. However, the public speaking experience item's results suggests that, on the basis of delivering one speech (and one short rebuttal speech), students felt that they had significantly increased their overall public speaking experience. This suggests that the students' frame of reference for thinking about public speaking experience is a fairly low one, consisting of only giving a few speeches publically. This finding is consistent with the comments students make when entering HUFS GSIT regarding their public speaking experience and their initial performances, which tend to be weak.

\section{LIMITATIONS AND SUGGESTIONS FOR FURTHER RESEARCH}

While the results of this study were positive, there were some significant limitations. The first and most prominent limitation is that the measurable impact on interpretation itself was lacking. To be fair, it is unlikely that a single public speaking exercise would revolutionize students' interpretation skills, so the study looked at individual components related to interpretation to identify avenues of progress. A further study of a total curriculum of forensics-based language training tasks and their impact on students' total interpretation abilities would definitely be merited on the basis of this study's results and could yield new insights into effective interpreter training.

Another drawback, not limited to this study, was the method of measuring the growth of the students' abilities. Students' were asked to assess their own abilities and as such their assessment may be flawed. Most means in the survey contained standard deviations around 2 which suggests that students vary greatly in their selfassessment and perhaps in their starting abilities. To the latter point, it should be noted that linguistic and interpreting skills would tend to vary with any interpreter training program. Additionally, given the variance in student ability, it is unclear how much the study would have benefited from having a control group. It should be noted that, within the program at HUFS GSIT, it was impossible to create a true control group that would not be working on impromptu speaking exercises in one of their other B language support classes during the same time period.

\section{CONCLUSION}

A future study should involve some type of triangulation to assess the precise growth of students from this learning task. Doing this will be a challenge since it will require several qualified observers to judge the performance of students before the activity and after the activity, which is not easy arrange and it may not be feasible to look at all the attributes covered in the students' self-assessment. What may be more manageable is narrowing doing the attributes in question to the items that saw the greatest levels of self-reported improvement like public speaking ability, or public speaking in English.

The author hopes that this study will provide interpretation training programs with some additional insight into the kinds of language tasks best suited for improving the skills of interpreters. Additionally the author hopes that this learning task can inspire some language teachers to try to use forensics-based tasks in the language classrooms to help improve foreign language speaking confidence. The learning task can be easily altered to fit into a variety of programs and content goals.

\section{ACKNOWLEDGMENT}

This paper was supported by the 2013 Research Fund of Hankuk University of Foreign Studies, South Korea. 


\section{AUTHOR INFORMATION}

Michael Heinz lectures fulltime at Hankuk University of Foreign Studies in the Graduate School of Interpretation and Translation. There he teaches interpreters in training public speaking skills, stress management skills, critical thinking skills, and general academic skills to prepare them to work as both consecutive and simultaneous interpreters. Working with interpreters affords him the unique opportunity to research high level language learning tasks and profile the traits of successful language learners of two vastly differing languages like English and Korean. Michael Heinz earned both his B.S. in History and his Master of Arts in Education from Truman State University. E-mail: michaelhistory@gmail.com

\section{REFERENCES}

1. Colina, S. (2002). Second language acquisition, language teaching and translation studies. The Translator, 8(1), 1-24.

2. Donovan, C. (2004). European Masters Project Group: Teaching simultaneous interpretation into a B language. Interpreting 6(2), 205-216.

3. Le Feal, K. (2000). Perfecting Active and Passive Languages: As a Conference Interpreter. Conference Interpretation and Translation 2, 7-23.

4. Lim, H. (2001). Teaching Interpretation and Translation. Conference Interpretation and Translation, 3, 211-242.

5. Minns, P. (2002). The Teaching of Interpretation into B: Some Conclusions Gathered from 25 years of Training Experience. Conference Interpretation and Translation 4(2), pp. 29-40.

6. Morell, J. L. R. (2011) Toward the development of a metacognitive intercultural communicative competence in the education of students of interpreting: general theoretical/ pragmatic foundations. Interpreting and Translating 3(1), 106-118.

7. Neubert, A. (1995). Competence in translation: a complex skill. how to study and how to teach it. In SnellHornby, M. Pöchhacker, F. \& K. Kaindl (Eds.), Translation Studies: An Interdiscipline (p. 411-420). Amsterdam: Benjamins.

8. Nolan, J. (2005). Interpretation: Techniques and Exercises. Clevedon: Multilingual Matters.

9. Reynolds, C. L. \& Fay, M. (1987). Competitive Impromptu Speaking. National Forensic Journal, 5, 8194.

10. Sellnow, D. D. (1994) Justifying Forensic Programs to Administrators: An experiential education opportunity. National Forensic Journal 11, 1-14.

11. Williams D.E., Carver C.T., \& Hart R.D. (1993). Is it Time for a Change in Impromptu Speaking? National Forensic Journal, 11, 29-4. 


\section{APPENDIX A: SELF-ASSESSMENT SURVEY}

Directions: For the following questions please rate your abilities on a scale of 1 to 10. A score of one indicates a low level of ability while a ten indicates a high level of ability.

1. Dependency on using notes while giving a public speech.

$$
\begin{array}{llllllllllll}
\text { (Low) } & 1 & 2 & 3 & 4 & 5 & 6 & 7 & 8 & 9 & 10 & \text { (High) }
\end{array}
$$

2. Dependency on intensive preparation (memorizing a public speech).

$$
\begin{array}{llllllllllll}
\text { (Low) } & 1 & 2 & 3 & 4 & 5 & 6 & 7 & 8 & 9 & 10 & \text { (High) }
\end{array}
$$

3. Ability to persuade others or advocate a position.

$$
\begin{array}{llllllllllll}
\text { (Low) } & 1 & 2 & 3 & 4 & 5 & 6 & 7 & 8 & 9 & 10 & \text { (High) }
\end{array}
$$

4. Ability to cope with the stress of public speaking.

$$
\begin{array}{llllllllllll}
\text { (Low) } & 1 & 2 & 3 & 4 & 5 & 6 & 7 & 8 & 9 & 10 & \text { (High) }
\end{array}
$$

5. Ability to use English when speaking publically.

$$
\begin{array}{llllllllllll}
\text { (Low) } & 1 & 2 & 3 & 4 & 5 & 6 & 7 & 8 & 9 & 10 & \text { (High) }
\end{array}
$$

6. Overall public speaking ability.

$$
\begin{array}{llllllllllll}
\text { (Low) } & 1 & 2 & 3 & 4 & 5 & 6 & 7 & 8 & 9 & 10 & \text { (High) }
\end{array}
$$

7. Impromptu speaking ability.

$$
\begin{array}{llllllllllll}
\text { (Low) } & 1 & 2 & 3 & 4 & 5 & 6 & 7 & 8 & 9 & 10 & \text { (High) }
\end{array}
$$

8. Public speaking experience.

$$
\begin{array}{llllllllllll}
\text { (Low) } & 1 & 2 & 3 & 4 & 5 & 6 & 7 & 8 & 9 & 10 & \text { (High) }
\end{array}
$$




\section{APPENDIX B: RESOURCES UTILIZED IN THE LEARNING TASK ORGANIZED BY TOPIC}

1. Foreign Aid

- John Stossel-Foreign Aid: http://www.youtube.com/watch?v=5VgfE0QYhF0

- William Easterly Aid to Africa Debate: http://www.youtube.com/watch?v=vzy8dafM89E

- Jeffery Sachs on CBC: http://www.youtube.com/watch?v=CNWzYy186W8

2. Intellectual Property

- Is Copying Theft?: http://www.youtube.com/watch?v=tPXIdernck0

- "Copyright": http://www.youtube.com/watch?v=eEB5MYcj-Ns\&feature=related

3. Free Trade versus Fair Trade

- Global Economics: Free Trade and Protection: http://www.youtube.com/watch?v=xRJZWfqWcs0

- Fair Trade-The Story: http://www.youtube.com/watch?v=NhQJrz-aDfI

4. Transhumanism

- Max More-Transhuman and the Singularity: http://www.youtube.com/watch?v=1xIQgBXw9-o

- Michael Sandel-Designer Children: http://www.youtube.com/watch?v=aFcfygkMM0I 